\section{Endoscopic submucosal dissection}

\section{Carlos Robles-Medranda}

Endoscopy and Gastroenterology Division, Ecuadorian Institute of Digestive Diseases (IECED), University Hospital OMNI, Universidad de Especialidades Espiritu Santo (UEES), Ecuador

\begin{abstract}
Endoscopic submucosal dissection (ESD) is a minimally invasive technique developed by Japanese endoscopists that allows one-piece endoscopic removal of early malignant lesions in the gastrointestinal tract. There is now a large and ever-increasing number of reports worldwide, and in the West use of this technique is on the increase. New materials and techniques have been developed to improve the technical aspects of ESD. Recent reports show successful clinical outcomes and improved overall 5-year survival rates for this technique. This review aims to offer an update of ESD based on the latest reports in the literature.
\end{abstract}

\section{Introduction}

Endoscopic submucosal dissection (ESD) is an innovative technique that has improved the rate of successful en bloc resection of large early gastrointestinal neoplasia. Since its introduction, ${ }^{1,2}$ new devices and techniques have been developed to improve the outcomes of ESD. Nowadays, these improvements have allowed ESD resections to be extended from stomach to other gastrointestinal mucosal areas, such as esophagus, duodenum, colon and rectum..$^{3,4}$ Moreover, when comparing endoscopic mucosal resection (EMR) with ESD for superficial neoplastic lesions, ESD is currently considered the best endoscopic resection method for lesions with diameters over $20 \mathrm{~mm}^{3}$ due to the higher curative resection rates, less risk of recurrence, and better histological assessment obtained by this technique. In spite of the better results obtained and the experience gained over time, this technique remains technically difficult, demanding particular endoscopic skills from operators. It also involves a longer procedure time with associated risks of complications such as bleeding and perforation. This article is a summary and update review of ESD based on new reports found in the literature.

\section{Technical aspects}

After endoscopic detection and histological diagnosis of an intramucosal neoplasia, ESD is performed using a standard single accessory channel endoscope. Marking dots are placed by electrocautery to delimitate the margins of the lesion to be resected. Using an injection needle, a submucosal fluid cushion is created to lift the mucosa from the submucosa layer, isolate the lesion and protect the muscularis propria from thermal and mechanical injury, reducing the risk of perforation. A circumferential incision is performed around the lesion using special electrocautery knives, and a submucosal dissection is finally performed with special knives to remove the specimen (Figures 1 and 2).

Finally, the removed specimen is pinned on a corkboard, oriented and placed in formalin for correct analysis with standard histological techniques.

\section{Materials and Methods}

Many types of endoscopic electrocautery knives have been developed to perform ESD (Figure 3): a needle knife, ${ }^{5}$ an insulationtipped (IT) knife 1 and 2,-12 a hook knife, ${ }^{13} \mathrm{a}$ flex knife, ${ }^{14}$ a flush knife, ${ }^{15}$ a triangular-tipped (TT) knife, ${ }^{16}$ a fork knife, ${ }^{17}$ and the recently introduced dual knife, ${ }^{18}$ hybrid knife ${ }^{19}$ and the splash needle. ${ }^{20}$ Each knife has its own characteristic regarding its design: diameter, length and the form of the tip, as well as rigidity (in the case of the flex knife). These characteristics mean there are both some advantages and disadvantages in its use regarding the direction of the incision, depth of the incision and coagulation properties. In some cases, additional characteristics such as multiple materials, injectors, or snares are presented in the same knife. This is the case of the flush, hybrid, dual and fork knives. The characteristics of each knife are summarized in Table 1.

The use of an electrosurgical unit with endocut properties is required to perform the cut and promote coagulation during ESD. For these purposes, generators, such as the ERBOTOM ICC 200, the VIO 300D (ERBE, Tübingen, Germany), or the recently introduced ESG-100 (Olympus Medical System Co. Ltd., Tokyo, Japan) (Figure 4), are available.

\section{Submucosal injection solution}

Injection-assisted endoscopic resection has been traditionally used to remove sessile or flat neoplastic lesions from the gastrointestinal tract. As has been proposed, an ideal solution for ESD should be inexpensive, easily available, non-toxic, easy to inject and able to provide a long-lasting submucosal cushion..$^{21,22}$
Correspondence: Carlos Robles-Medranda, Instituto Ecuatoriano de Enfermedades Digestivas - IECED, Hospital Universitario OMNI, Universidad de Especialidades Espiritu Santo, Torre Vitalis, Mezanine 1. Av. Abel Romeo Castillo y Av. Juan Tanca Marengo, Guayaquil, Ecuador.

Tel. +593.42109180 - Fax: +593.52633265 .

E-mail: carlosoakm@yahoo.es

Key words: endoscopic submucosal dissection, ESD, gastric ESD, esophageal ESD, water-jet ESD, ESD review, colonic ESD.

Acknowledgment: David E. Lukashok.

Conflict of interests: the authors declare no potential conflict of interests.

Received for publication: 26 September 2011. Accepted for publication: 1 March 2012.

This work is licensed under a Creative Commons Attribution NonCommercial 3.0 License (CC BYNC 3.0).

(c) Copyright C. Robles-Medranda 2012

Licensee PAGEPress, Italy

Gastroenterology Insights 2012; 4:e10

doi:10.4081/gi.2012.e10

Saline solution ( $\mathrm{NaCl} 0.9 \%)$ has been largely used for endoscopic mucosal resection either alone or in combination with epinephrine. ${ }^{23}$ However, in spite of it being a seemingly ideal solution, the duration of the normal saline solution is short and, therefore, not ideal for the purposes of ESD.

Other solutions have been demonstrated to be superior to $\mathrm{NaCl} 0.9 \%$ in creating a longlasting submucosal fluid cushion (SFC) such as a hypertonic solution of sodium chloride (3.0\%), glycerol, dextrose $(20 \%, 30 \%, 50 \%)$, albumin, fibrinogen, autologous blood, hyaluronic acid and the hydroxypropyl methylcellulose. $^{24-30}$ The advantages and disadvantages of each solution include its availability in the endoscopy units, its price (how expensive it is), and whether or not it can produce tissue damage or local inflammation. Today, the best cushion duration available is obtained with substances such as hyaluronic acid, hydroxypropyl methylcellulose, fibrinogen and autologous blood. Recently, other substances such as polyvinyl alcohol $1.4 \%$, hydroxyethyl starch $6 \%$ and polyethylene glycol have been demonstrated to be superior to normal saline solution and to perform equally as well as sodium hyaluronate in an ex vivo study. ${ }^{30}$

\section{Drawbacks and new developments}

Many studies have demonstrated the feasibility and efficacy of ESD for treating gastrointestinal lesions. The drawback of ESD is that it 
is technically difficult to perform and is, therefore, associated with long operating time and higher rates of complications. ${ }^{8,12,31}$ In addition, ESD requires advanced endoscopic techniques. ${ }^{31}$ Imagawa et al. show that the difficulty of ESD depends on: location, size (>20 mm) and characteristics of the lesion (ulcerated lesions) as well as the endoscopist's experience. $^{32}$

There are important technical aspects to be considered during ESD: the placement of the endoscope under the submucosal layer to obtain direct visibility during dissection and the long-lasting SFC required to reduce the time needed for the procedure and to avoid complications. As far as long-lasting SFC is concerned, many substances have been tested for ESD (see above) and have shown good results. Adaptable caps on the tip of the endoscope can be used to facilitate the positioning of the endoscope under the submucosal layer.

Recently, other materials and techniques have been developed for the same purpose, such as the use of clips for peroral tractionassisted ESD, ${ }^{33}$ clips for internal counter-traction spring devices ${ }^{34}$ and a permalloy tissue anchor for external magnetic force-assisted $\mathrm{ESD}^{35}$ all of which demonstrate the feasibility of the technique. However, some of these materials are not always available and cost issues sometimes limit their use for routine application in real clinical conditions.

\section{Water-jet technology}

Water-jet (WJ) technology was first introduced in flexible endoscopes to assist mucosal resections during bleedings, by washing the bleeding field with the WJ. The bleeding source can then be immediately identified and coagulated, avoiding the use of the syringe over the forceps channel of the endoscope. ${ }^{36}$

WJ technology is under investigation as a medical tool in many other surgical areas. It has demonstrated a clear technical advantage over the conventional surgical dissection modalities. It allows: i) a selective dissection of fibrous and connectives tissues, preserving blood vessels for delayed ligation; ${ }^{37-39}$ ii)

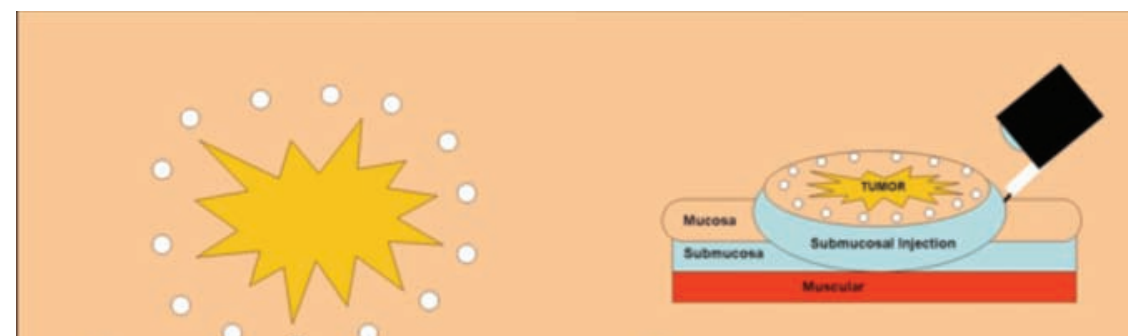

A

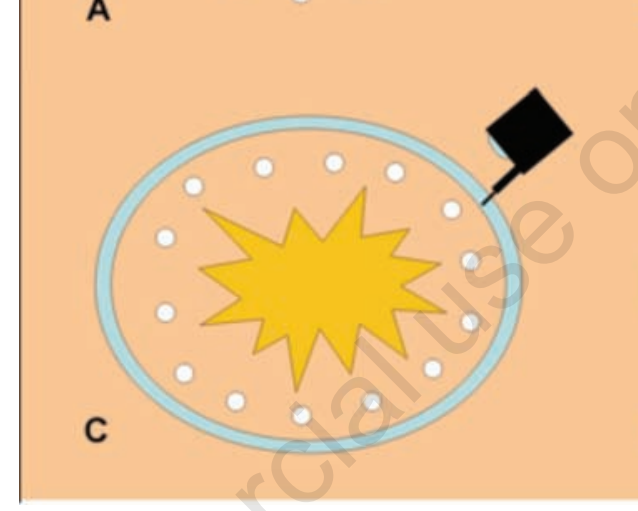

B

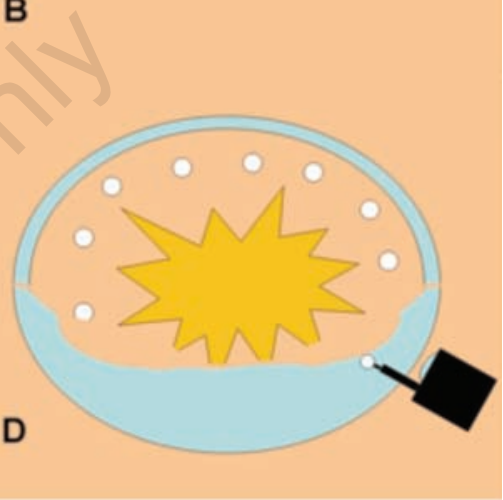

Figure 1. Endoscopic submucosal dissection schematic steps. A) Marking dots to delimitate the lesion; B) Submucosal injection; C) Circumferential incision; D) Submucosal dissection.

Table 1. Characteristics of endoscopic submucosal dissection knifes.

\begin{tabular}{|c|c|}
\hline Name (Manufactrer) & Characteristics \\
\hline Needle knife (Olympus®, Boston®, Cook®) & Needle tip with adjustable length. High risk of perforation \\
\hline Insulation Tipped knife 1: IT-knife 1 (Olympus@) & $\begin{array}{l}\text { Small ceramic ball on the tip of a needle knife. Prevents perforations. } \\
\text { Can not operate in any direction, does not permits coagulation. Can not be used for injection }\end{array}$ \\
\hline Insulation Tipped knife 2: IT-knife 2 (Olympus@) & $\begin{array}{l}\text { Small ceramic ball on the tip of a triangle tip knife. Prevents perforation, it permits to cut and } \\
\text { to coagulate. Can not be used for injection }\end{array}$ \\
\hline Flex knife (Olympus@) & $\begin{array}{l}\text { Soft and flexible cutting, rounded tip with a twisted wire. Flexible tip that prevents perforations, } \\
\text { permits to cut and to coagulate. Can not be used for injection }\end{array}$ \\
\hline Flush knife (Fujinon®) & $\begin{array}{l}\text { Water jet fine needle knife with regulated length. Avoid exchange between knife and the injection } \\
\text { needle. Allows washout of blood }\end{array}$ \\
\hline Triangle Tip knife: TT-knife (Olympus®) & Triangle form at the tip. It permits to cut and to coagulate. It can operate in any direction. Risk of perforation \\
\hline Fork knife (Endo FS®) & $\begin{array}{l}\text { Two knifes: a forked knife, fixed flexible snare and an inlet for material injection. } \\
\text { Avoid exchange between knife and the injection needle. Single working unit }\end{array}$ \\
\hline Dual knife (Olympus®) & $\begin{array}{l}\text { Water jet with a rounded needle knife with regulated length. } \\
\text { Avoid exchange between knife and the injection needle. Allows washout of blood }\end{array}$ \\
\hline Hook knife (Olympus®) & $\begin{array}{l}\text { Right angle bend of the needle knife tip. The tip is rotable and can pull dissect the tissue. } \\
\text { It permits to cut and to coagulate. It can operate in any direction. High risk of perforation }\end{array}$ \\
\hline Splash needle (Pentax®) & $\begin{array}{l}\text { Water jet fine needle knife with regulated length. Avoid exchange between knife and the injection needle. } \\
\text { Allows washout of blood }\end{array}$ \\
\hline Hybrid knife (ERBE@) & Water jet fine needle knife. Avoid exchange between knife and the injection needle. Allows washout of blood. \\
\hline
\end{tabular}


reduction in dissection-related complications; ${ }^{38,40}$ iii) reduction in tissue injury; ${ }^{40}$ and iv) reduction in dissection time compared with conventional techniques. ${ }^{41}$ Based on these observations, in 2007 two reports described the application of water-jet technology as a technique used together with ESD. ${ }^{42,43}$ Lepilliez et al. ${ }^{42}$ describe the use of WJ as two techniques in a porcine model: i) as an injection technique; and ii) as a dissection method with a catheter prototype and using the water as a dissection method. In this report, the feasibility and possible applications of WJ technology for stomach and esophageal ESD were demonstrated. At the same time, Toyonaga et al. ${ }^{43}$ also demonstrated use of WJ technology in ESD as an injection method with the flush knife, facilitating the dissection by thermal coagulation. WJ technology seems to facilitate ESD. This could be due to the speed and quality of injection using provided by the WJ that allows a longer lasting SFC. Kaehler et al. ${ }^{44}$ demonstrated that submucosal injection of a saline solution using WJ provides a selective long-lasting SFC for over $20 \mathrm{~min}$. These results were confirmed by the same team in a study on humans obtaining long-lasting SFC for over 40 min using other solutions such as plasma expanders. ${ }^{45}$ Today, the number of clinical trials using the WJ technology is on the increase as are the devices developed for its use. ${ }^{19,36,46}$

\section{Learning curves}

Japanese physicians have suggested some criteria that they consider should be required before performing $\mathrm{ESD},{ }^{47}$ such as: i) attendance at ESD pre- and post-treatment conferences; ii) initial experience as an assistant physician during ESD procedures for at least one year; iii) skillful recognition of the extent and depth of the tumors; and iv) expertise in hemostasis.

Previous studies have investigated the learning curves for ESD. ${ }^{48-50}$ Choi et al. ${ }^{48}$ have found an increase in the en bloc resection rate from $45-85 \%$ after an experience of 40 cases. Gotoda et al. ${ }^{49}$ reported that experience of at least 30 cases is required for a beginner to gain early proficiency in ESD. Kakushima et al. ${ }^{50}$ have indicated that a change in en bloc complete resection and complication rates did not represent operator proficiency with ESD under supervision, but that a reduction in operation time is a marker of proficiency. According to them, this is only acquired with time and a minimum number of cases.

Recently, an interesting and well-designed report from Yamamoto et al. ${ }^{47}$ showed that experience of more than 30 cases is necessary in order to become proficient.
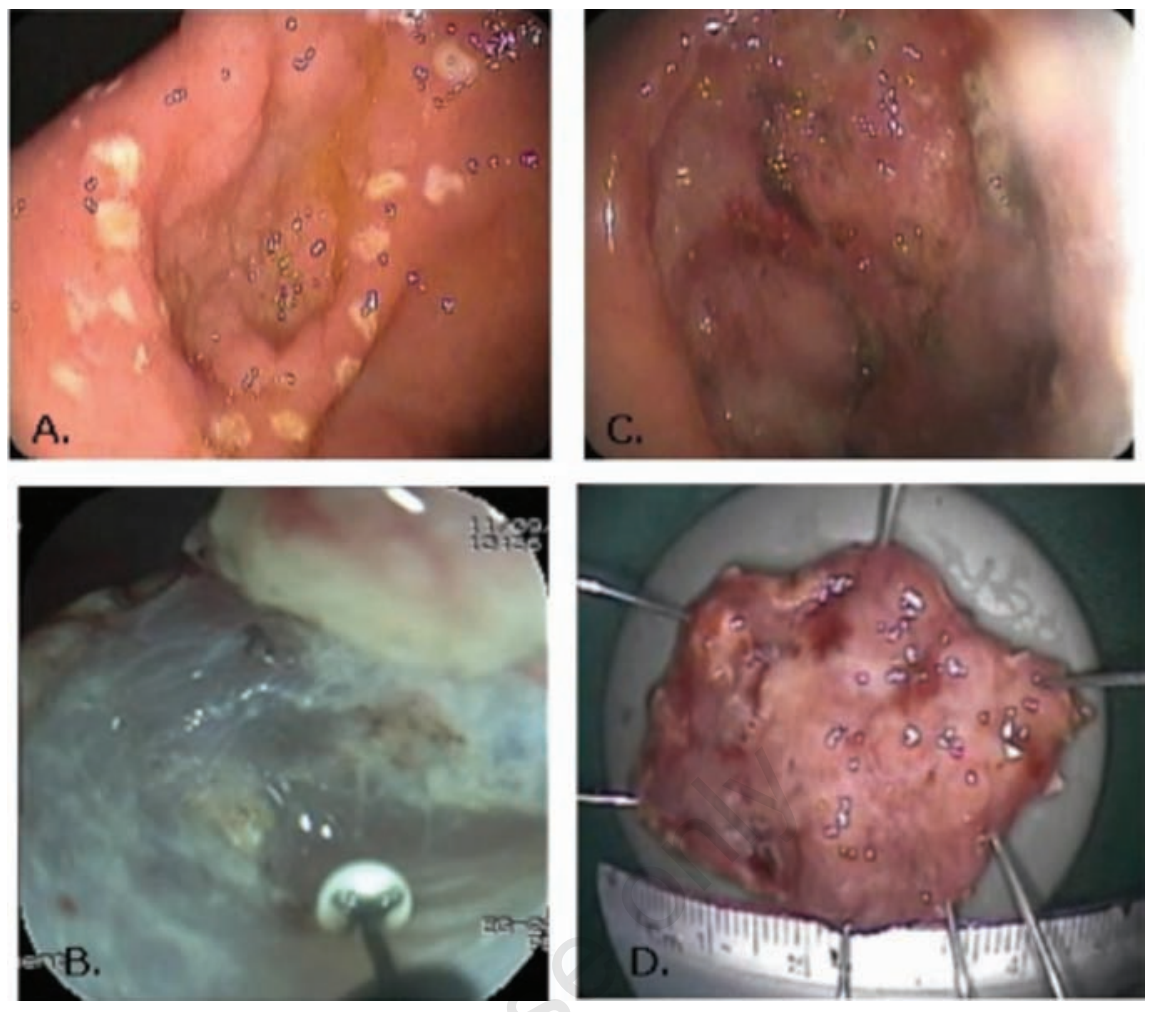

Figure 2. Endoscopic submucosal dissection of an early gastric cancer type 0-IIa from the antrum. A) Marking dots around the lesion; B) Submucosal dissection using IT-knife 2; C) The mucosal ulcer after complete resection of the lesion; D) The mucosal tumor of 40 $\mathrm{mm}$ of diameter resected in one piece.

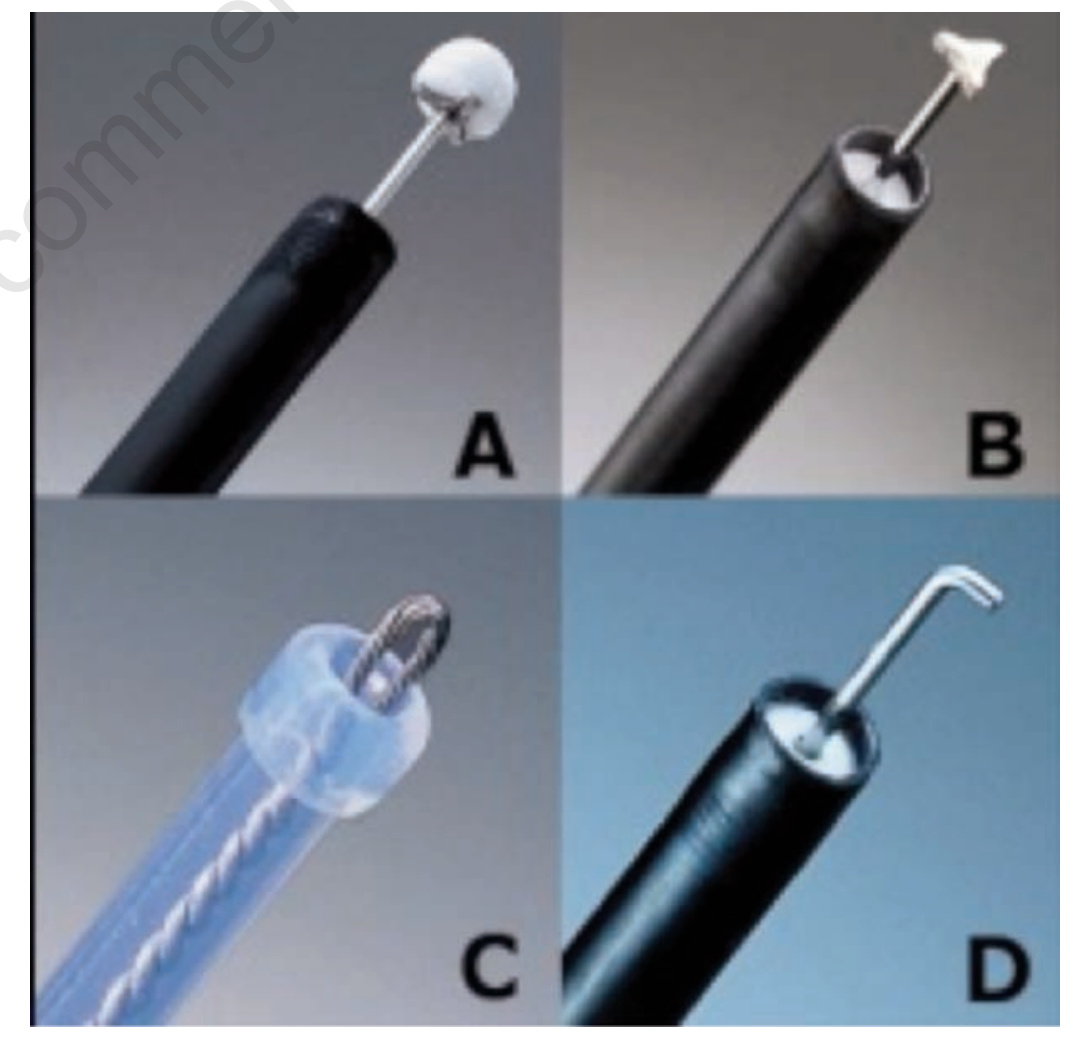

Figure 3. Electrocautery knives for Endoscopic submucosal dissection. A) Insulationtipped knife (IT-knife 2); B) triangle-tip knife (TT-knife); C) flex knife; D) hook knife (pictures courtesy from Olympus Latinamerica). 


\section{Clinical applications and efficacy at follow up}

ESD is generally indicated for resections of intramucosal neoplastic lesions of more than $20 \mathrm{~mm}$. Initially, it was created to treat early gastric cancers but the development of new materials, as well as the performance of the endoscopists, have allowed this method to be extended to other parts of the gastrointestinal tract, such as the esophagus, duodenum, colon and rectum. It is very important to have a good staging of the lesions with complementary studies before performing ESD. It is also important that the extent of the lesion is appropriate. For this purpose, the use of magnifying endoscopy, chromoendoscopy and new endoscopy technology, such as narrow band imaging (NBI) (Olympus Optical Co., Tokyo, Japan), and/or the intelligent-scan system (iScan) (Pentax Corporation, Tokyo, Japan) (Figure 5) could be of help.51,52

\section{Endoscopic submucosal dissec- tion for upper gastrointestinal tumors}

\section{Esophagus}

In the esophagus, ESD is indicated for the treatment of moderated and well-differentiated epidermoid cancer and recently it has also been proposed as a therapeutic approach in high-grade dysplasia in Barrett's esophagus and the adenocarcinoma. ${ }^{53-55}$ The lesions should be located in the mucosal layer and there should be no lymph node involvement (T1N0). The absolute indication for endoscopic resection in cases of epidermoid cancer is defined as $\mathrm{ml}$ (restricted to the propel mucosa) -m2 (adjacent or invading but not beyond the muscularis mucosa) esophageal cancer plus no more than two-thirds extension of the circumference..$^{54}$ In a recent report, Higuchi $e t$ al ${ }^{56}$ showed that an extension of these indications could be achieved for lesions involving $\mathrm{m} 3$-sml esophageal cancer, without lymphatic invasion, larger surface dimensions, and wider lamina muscularis mucosae invasion. 0n the other hand, $\mathrm{m} 3$ or sm1 lesions accompanied by lymphatic invasion confirmed after endoscopic resection should be treated as a systemic disease with high risk of lymphnode metastasis. ${ }^{53}$ A 5 -year survival rate for lesions limited to the lamina propria mucosa has been reported in $100 \%$ of such cases and $86 \%$ for lesions deeper than the lamina propia mucosa. ${ }^{57}$ Barrett's esophagus often has double muscularis mucosae, therefore the depth of invasion should be subdivided into $\mathrm{m} 1-\mathrm{m} 4 .{ }^{55} \mathrm{In}$ these cases, endoscopic resection is indicated for lesions limited to the mucosa and in

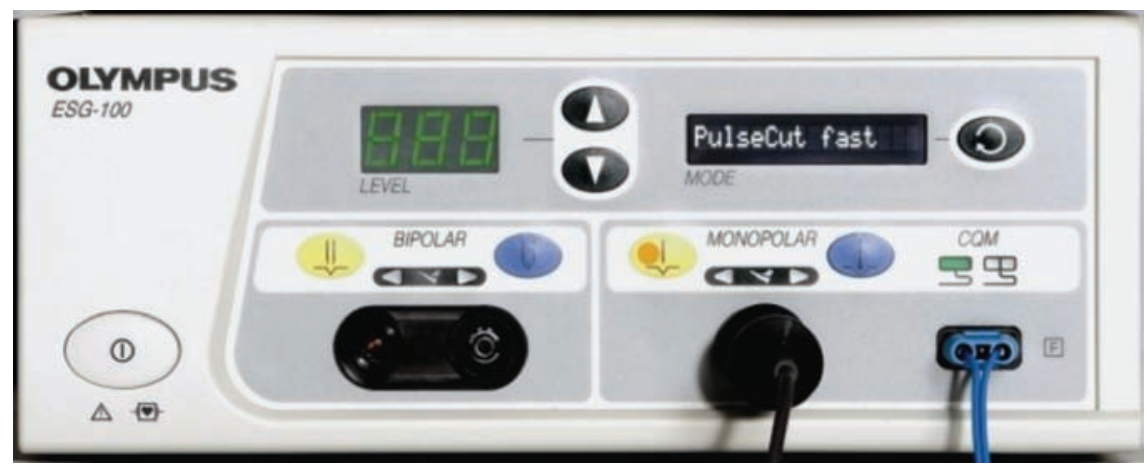

Figure 4. The electrosurgical unit with endocut properties ESG-100 (picture courtesy from Olympus Latinamerica).

lesions with high-grade dysplasia where the risk of lymph-node metastases or micrometastases is often absent. ${ }^{55,58} \mathrm{~A} 5$-year survival rate of $98 \%$ has been reported after endoscopic treatment of these lesions. ${ }^{59}$

\section{Stomach}

The first application of ESD was in gastric cancer. The literature reports that more than 10,000 of these types of lesions have been treated. ESD is indicated for differentiated type intramucosal cancer without ulcer, differentiated type intramucosal cancer no larger than $3 \mathrm{~cm}$ in diameter with ulcer, and differentiated type minute invasive submucosal cancer $(<500$ micrometers below the muscularis mucosa). Cancerous lesions no larger than $3 \mathrm{~cm}$ in diameter are now considered as indications for endoscopic resection..$^{60}$ A 5 -year survival rate for lesions limited to the lamina propria mucosa has been reported in around of 96 to $100 \%$ of cases. ${ }^{61}$ ESD has also been reported in submucosal lesions specifically when the tumors display a submucosal layer or muscularis mucosa origin, ${ }^{62}$ as well as for the treatment of neoplasms arising from the remnant stomach after gastrectomy or esophagectomy.63 But these results are limited to a case series.

\section{Duodenum}

Recent reports have shown the use of ESD for duodenal lesions. Honda et al.$^{64}$ described the feasibility of ESD for duodenal neoplasm in a series of cases. The authors concluded that duodenal ESD remains a technique demanding time-consuming procedures, and is associated with a high risk of complications. Fukushima et al. reported the first en bloc resection of a large ampullary adenoma with focal adenocarcinoma by using ESD. ${ }^{65}$ However, these experiences are restricted to a case series and follow-up results remain unclear.

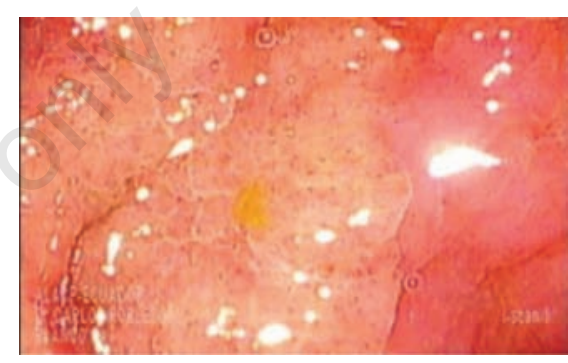

Figure 5. Macroscopic aspect of a segment of an early gastric cancer: meshed capillary vessels are observed with the $i$-scan system and magnification (Pentax Corporation, Tokyo, Japan).

\section{Endoscopic submucosal dissec- tion for lower gastrointestinal tumors}

\section{Ileum, colon and rectum}

Endoscopic resection is indicated for the treatment of adenoma and intramucosal or submucosal superficial (sm1: less than 1000 $\mu \mathrm{m}$ from the muscularis mucosae) colorectal cancer because of its minimal invasiveness, negligible risk of lymph-node (LN) metastasis 1 and excellent results in terms of clinical outcome. ${ }^{66-68}$

In colorectal mucosal cancer, endoscopic piecemeal mucosal resection (EPMR) can treat many LSTs over $20 \mathrm{~mm}$ with only a few cases requiring surgery. ${ }^{69}$ Recently, an increasing number of colorectal ESDs have been reported from Japan showing the feasibility of the technique, especially in lateral spread tumors of the non-granular type. ${ }^{70-72}$ Furthermore, a case series study of colorectal ESD, published by Niimi et al. shows that the 5-year survival rate is as high as $95.3 \%{ }^{73}$ 
Table 2. Rates of bleeding and perforation in endoscopic submucosal dissection in accordance to the location of the mucosal resection reported by some authors.

\begin{tabular}{lccc}
\hline Location & Total Cases & Bleeding \% & Perforation \% \\
Esophageal $^{74}$ & 58 & 0 & 6.9 \\
Stomach $^{75}$ & 1033 & 4 & 1 \\
\hline Colorectal $^{77}$ & 292 & 0.7 & 8.2 \\
\hline
\end{tabular}

Finally, a case report of ESD in the terminal ileum by Japanese endoscopists ${ }^{74}$ shows the feasibility of this technique in this area.

\section{Complications}

The great majority of complications arising from ESD are bleeding and perforation. ${ }^{75-78}$ Most are, however, solved during the procedure. In an interesting study, Takizawa et al. ${ }^{77}$ show that the experience of the operators does not influence delayed bleeding after gastric ESD. However, the tumor location and postESD coagulation are important factors in postESD bleeding risk, which indicates that preventive coagulation should be routinely performed. Isomoto et al. ${ }^{78}$ reported that the clinicopathological factors associated with colorectal ESD are essentially large tumor size and presence of fibrosis. Hemostasis is required as well as a good visibility when performing ESD. For hemostasis, the use of a thermal coagulation grasper, hemoclips, esclerotherapy needles, and an argon plasma coagulator are used. To maintain good visibility during bleeding, water-jet irrigation endoscopes and/or irrigation pumps are available. To treat perforation, endoscopy clips have been used with good results. ${ }^{78}$

The rates of bleeding and perforation related to the esophagus, stomach and colon are summarized in Table 2. Other types of complications have been described. These concern pain, stricture and bacteremia. ${ }^{79-81}$ In cases of stricture, it has been proposed that large circumferential resections should be avoided. ${ }^{79}$ The use of cellular therapy, such as extracellular matrix scaffold or autologous buccal keratinocyte implantation, has shown promising results in the prevention of esophageal strictures after circumferential mucosal resection. ${ }^{82,83}$ Finally, when there is post-ESD stricture, the use of repeated balloon dilations might constitute a useful option. ${ }^{79}$ Nevertheless, we still need to develop low-cost and low-risk techniques that are readily available. Mention should also be made of post-procedural discomfort after ESD. This is observed in some patients and often attributed to air insufflations during the procedure. This problem is largely controlled nowadays by the use of $\mathrm{CO}_{2}$ pumps, as suggested by Saito et al. ${ }^{84}$ in a recent study.

\section{Endoscopic submucosal dissection in Western countries}

To acquire the necessary expertise in ESD, operators need to carry out a minimum number of procedures and methodology in training is important. In the West, experience of ESD is limited to reference centers with a low number of cases reported. ${ }^{85}$ This limitation could be due to several conditions, ${ }^{86}$ which include screening systems to detect early gastrointestinal cancers, the relative infrequency of early gastric cancer in many Western countries, the differences in the evaluation criteria between Japanese and Western pathologists, and the low number of structured training courses.

\section{Summary and perspectives}

Nowadays, ESD is without doubt an efficient technique for the treatment of early gastrointestinal tumors with good results at follow up. accurate pre-operative diagnosis, and familiarity with the correct indications for ESD are indispensable to ensure successful treatment.

Despite the excellent results achieved so far, more progress could be made in reducing timeconsuming or risky procedures and perfecting general techniques. Western experience and expertise in advanced techniques is still far behind that of Japan. In the West, improved techniques and early screening, as well as better training of endoscopists, are still required in order to achieve positive results.

\section{References}

1. Hirao M, Masuda K, Asanuma T, et al. Endoscopic resection of early gastric cancer and other tumors with local injection of hypertonic saline-epinephrine. Gastrointest Endosc 1988;34:264-9.

2. Kakushima N, Fujishiro M. Endoscopic submucosal dissection for gastrointestinal neoplasms. World J Gastroenterol 2008;14: 2962-7.

3. Ishihara $\mathrm{R}$, Iishi $\mathrm{H}$, Uedo $\mathrm{N}$, et al. Comparison of EMR and endoscopic submucosal dissection for en bloc resection of early esophageal cancers in Japan. Gastrointest Endosc 2008;68:1066-72. Early detection of gastrointestinal tumors,
4. Gotoda T, Kondo H, Ono $\mathrm{H}$, et al. A new endoscopic resection procedure using an insulation-tipped electrosurgical knife for rectal flat lesions: report of two cases. Gastrointest Endosc 1999;50:560-3.

5. Hirao M, Masuda K, Asanuma T, et al. Endoscopic resection of early gastric cancer and other tumors with local injection of hypertonic saline-epinephrine. Gastrointest Endosc 1988;34:264-9.

6. Muto M, Miyamoto S, Hosokawa A, et al. Endoscopic mucosal resection in the stomach using the insulated-tip needle-knife. Endoscopy 2005;37:178-82.

7. Oka S, Tanaka S, Kaneko I, et al. Advantage of endoscopic submucosal dissection compared with EMR for early gastric cancer. Gastrointest Endosc 2006;64: 877-83.

8. Ono H, Kondo H, Gotoda T, et al. Endoscopic mucosal resection for treatment of early gastric cancer. Gut 2001;48: 225-9.

9. Ohkuwa M, Hosokawa K, Boku N, et al. New endoscopic treatment for intramucosal gastric tumors using an insulated-tip diathermic knife. Endoscopy 2001;33:2216.

10. Miyamoto S, Muto M, Hamamoto Y, et al. A new technique for endoscopic mucosal resection with an insulated-tip electrosurgical knife improves the completeness of resection of intramucosal gastric neoplasms. Gastrointest Endosc 2002;55:57681.

11. Rösch T, Sarbia M, Schumacher B, et al. Attempted endoscopic en bloc resection of mucosal and submucosal tumors using insulated-tip knives: a pilot series. Endoscopy 2004;36:788-801.

12. Gotoda T. A large endoscopic resection by endoscopic submucosal dissection procedure for early gastric cancer. Clin Gastroenterol Hepatol 2005;3:S71-S73.

13. Oyama T, Tomori A, Hotta K, et al. Endoscopic submucosal dissection of early esophageal cancer. Clin Gastroenterol Hepatol 2005;3:S67-S70.

14. Yahagi N, Fujishiro M, Kakushima N, et al. Endoscopic submucosal dissection for early gastric cancer using the tip of an electro-surgical snare (thin type). Dig Endosc 2004;16:34-8.

15. Toyonaga T, Nishino E, Dozaiku T, et al. Management to prevent bleeding during endoscopic submucosal dissection using the flush knife for gastric tumors. Dig Endosc 2007;19:S14-S18.

16. Inoue $\mathrm{H}$, Sato $\mathrm{Y}$, Kazawa $\mathrm{T}$, et al. Endoscopic submucosal dissection-using a triangletipped knife. Sto Int 2004:39:53-6.

17. Kim HG, Cho JY, Bok GH, et al. A novel device for endoscopic submucosal dissection, the Fork knife. World J Gastroenterol 


\section{8;14:6726-32.}

18. Hirano N, Yahagi N, Yamashita S, et al. Useful of dual knife in endoscopic submucosal dissection for colorectal neoplasms. Endoscopy 2009;41:A91.

19. Fernández-Esparrach G, Matthes EL, Maurice D, et al. A novel device for endoscopic submucosal dissection that combines water-jet submucosal hydrodissection and elevation with electrocautery: initial experience in a porcine model. Gastrointest Endosc 2010;71:615-8.

20. Fujishiro M, Kodashima S, Goto 0, et al. Successful en bloc resection of superficial esophageal cancer treated by endoscopic submucosal dissection with a splash needle. Endoscopy 2008;40:E81-E82.

21. Giday SA, Magno P, Buscaglia JM, et al. Is blood the ideal submucosal cushioning agent? A comparative study in a porcine model. Endoscopy 2006;38:1230-4.

22. Yeh RW, Triadafilopoulos G. Submucosal injection: safety cushion at what cost? Gastrointest Endosc 2005;62:943-5.

23. Rösch T, Sarbia M, Schumacher B, et al. Attempted endoscopic en bloc resection of mucosal and submucosal tumors using insulated-tip knifes: A pilot series (including videos). Endoscopy 2004;36:788-801.

24. Yamamoto $\mathrm{H}$, Yube $\mathrm{T}$, Isoda $\mathrm{N}$, et al. A novel method of endoscopic mucosal resection using sodium hyaluronate. Gastrointest Endosc 1999;50:251-6.

25. Giday SA, Magno P, Buscaglia JM, et al. Is blood the ideal submucosal cushioning agent? A comparative study in a porcine model. Endoscopy 2006;38:1230-4.

26. Uraoka T, Fujii T, Saito Y, et al. Effectiveness of glycerol as a submucosal injection for EMR. Gastrointest Endosc 2005;61:736-40.

27. Fujishiro M, Yahagi N, Kashimura K, et al. Comparison of various submucosal injection solutions for maintaining mucosal elevation during endoscopic mucosal resection. Endoscopy 2004;36:579-83.

28. Feitoza AB, Gostout CJ, Burgart LJ, et al. Hydroxypropyl methylcellulose: a better submucosal fluid cushion for endoscopic mucosal resection. Gastrointest Endosc 2003;57:41-7.

29. Sato T. A novel method of endoscopic mucosal resection assisted by submucosal injection of autologous blood (blood patch EMR). Dis Colon Rectum 2006;49:1636-41.

30. Polymeros D, Kotsalidis G, Triantafyllou K, et al. Comparative performance of novel solutions for submucosal injection in porcine stomachs: An ex vivo study. Dig Liv Dis 2010;42:226-9.

31. Onozato $\mathrm{Y}$, Ishihara $\mathrm{H}$, lizuka $\mathrm{H}$, et al. Endoscopic submucosal dissection of early gastric cancers and large flat adenomas. Endoscopy 2006;38:980-6.
32. Imagawa A, Okada H, Kawahara Y, et al. Endoscopic submucosal dissection of early gastric cancer: results and degrees of technical difficulty as well as success. Endoscopy 2006;38:987-90.

33. Jeon WJ, You IY, Chae HB, et al. A new technique for gastric endoscopic submucosal dissection: peroral traction-assisted endoscopic submucosal dissection. Gastrointest Endosc 2009;69:29-33.

34. Sakurazawa N, Kato S, Miyashita M, et al. An innovative technique for endoscopic submucosal dissection of early gastric cancer using a new spring device. Endoscopy 2009;41:929-33.

35. Sumiyama K, Ohdaira T, Ikeda K, Tajiri H. Magnetic force assisted endoscopic submucosal dissection with permalloy tissue anchors. Gastrointest Endosc 2008;67: AB91.

36. Uedo N, Tatsumi K, Iishi H, et al. Effect of water-jet function on endoscopic submucosal dissection for early gastric cancer: a prospective randomized controlled trial. Gastrointest Endosc 2008;67:AB140.

37. Shekarriz H, Shekarriz B, Kujath P, et al. Hydro-jet assisted laparoscopic cholecystectomy: a prospective randomized clinical study. Surgery 2003;133:635-40.

38. Shekarriz H, Shekarriz B, Burk CG, et al. Hydro-jet-assisted pneumonectomy: a new technique in a porcine model. $\mathrm{J}$ Laparoendosc Adv Surg Tech A 2002;12: $371-6$.

39. Oertel J, Gaab MR, Knapp A, et al. Water jet dissection in neurosurgery: experimental results in the porcine cadaveric brain. Neurosurgery 2003;52:153-9.

40. Corvin S, Oberneder R, Adam C, et al. Use of hydro-jet cutting for laparoscopic partial nephrectomy in a porcine model. Urology 2001;58:1070-3.

41. Shekarriz B, Shekarriz H, Upadhyay J, et al. Hydro-jet dissection for laparoscopic nephrectomy: a new technique. Urology 1999:54:964-7.

42. Lepilliez V, Robles-Medranda C, Lukashok $\mathrm{H}$, et al. The use of waterjet technology in gastrointestinal endoscopy: an experimental study of two new techniques for endoscopic submucosal dissection. Gastrointest Endosc 2007;65:AB92.

43. Toyonaga T, Nishino E. Effectiveness of endoscopic submucosal dissection using flush knife for esophageal cancers. Gastrointest Endosc 2007;65:AB93.

44. Kaehler G, Sold MG, Fischer K, et al. Selective fluid cushion in the submucosal layer by water jet: advantage for endoscopic mucosal resection. Eur Surg Res 2007;39:93-7.

45. Kaehler G, Sold MG, Post S, et al. Selective tissue elevation by pressure injection (STEP) facilitates endoscopic mucosal resection (EMR). Surg Technol Int 2007;16:107-12.

46. Schumacher B, Mayershofer R, Charton JP, et al. Endoscopic submucosal resection of early gastric neoplasia with a water-jet hybridknife (esdh): a prospective western study in 31 patients. Gastrointest Endosc 2010;71:AB124.

47. Yamamoto $\mathrm{S}$, Uedo $\mathrm{N}$, Ishihara $\mathrm{R}$, et al. Endoscopic submucosal dissection for early gastric cancer performed by supervised residents: assessment of feasibility and learning curve. Endoscopy 2009;41: 923-8.

48. Choi IJ, Kim CG, Chang HJ et al. The learning curve for EMR with circumferential mucosal incision in treating intramucosal gastric neoplasm. Gastrointest Endosc 2005;62:860-5.

49. Gotoda T, Friedland S, Hamanaa H, Soetikno R. A learning curve for advanced endoscopic resection. Gastrointest Endosc 2005;62:866-7.

50. Kakushima N, Fujishiro M, Kodashima S, et al. A learning curve for endoscopic submucosal dissection of gastric epithelial neoplasms. Endoscopy 2006;38:991-5.

51. Sano Y, Ikematsu H, Fu Kl, et al. Meshed capillary vessels by use of narrow-band imaging for differential diagnosis of small colorectal polyps. Gastrointest Endosc 2009;69:278-83.

52. Kodashima S, Fujishiro M. Novel imageenhanced endoscopy with i-scan technology. World J Gastroenterol 2010;16:1043-9.

53. Yamamoto H. Technology insights: endoscopic submucosal dissection of gastrointestinal neoplasm. Nat Clin Pract Gastroenterol and Hepatol 2007;9:511-20.

54. Fujita H. Present status of esophageal cancer and its treatment in Japan. Ann Thorac Cardiovasc Surg 2004;10:135-9.

55. Vieth M, Stolte M. Pathology of early upper gastrointestinal cancers. Best Pract Res Clin Gastroenterol 2005;19:857-69.

56. Higuchi K, Tanabe S, Koizumi W, et al. Expansion of the indications for endoscopic mucosal resection in patients with superficial esophageal carcinoma. Endoscopy 2007;39:36-40.

57. Ono S, Fujishiro M, Niimi K, et al. Longterm outcomes of endoscopic submucosal dissection for superficial esophageal squamous cell neoplasms. Gastrointest Endosc 2009;70:860-6.

58. Sepesi B, Watson TJ, Zhou D, et al. Are endoscopic therapies appropriate for superficial submucosal esophageal adenocarcinoma? An analysis of esophagectomy specimens. J Am Coll Surg 2010;210:41827.

59. Ell C, et al. Curative endoscopic resection of early esophageal adenocarcinomas (Barrett's cancer). Gastrointest Endosc 
2007;65:3-10.

60. Soetikno R, Kaltenbach T, Yeh R, Gotoda T. Endoscopic mucosal resection for early cancers of the upper gastrointestinal tract. J Clin Oncol 2005;23:4490-8.

61. Goto 0, Fujishiro M, Kodashima S, et al. Outcomes of endoscopic submucosal dissection for early gastric câncer with special reference to validation for curability criteria. Endoscopy 2009;41:118-22.

62. Hoteya S, lizuka T, Kikuchi D, Yahagi N. Endoscopic submucosal dissection for gastric submucosal tumor, endoscopic subtumoral dissection. Dig Endosc 2009;21: 266-9.

63. Hoteya S, lizuka T, Kikuchi D, Yahagi N. Clinical advantages of endoscopic submucosal dissection for gastric cancers in remnant stomac surpass conventional endoscopic mucosal resection. Dig Endosc 2010;22: 17-20.

64. Honda T, Yamamoto H, Osawa H, et al. Endoscopic submucosal dissection for superficial duodenal neoplasms. Dig Endosc 2009;21:270-4.

65. Fukushima H, Yamamoto H, Nakano H, et al. Complete en bloc resection of a large ampullary adenoma with a focal adenocarcinoma by using endoscopic submucosal dissection. Gastrointest Endosc 2009;70: 592-5.

66. Ahmad NA, Kochman ML, Long WB, ET al. Efficacy, safety, and clinical outcomes of endoscopic mucosal resection: A study of 101 cases. Gastrointest Endosc. 2002;55: 390-6.

67. Yokota T, Sugihara K,Yoshida S. Endoscopic mucosal resection for colorectal neoplastic lesions. Dis Colon Rectum 1994;37:1108-11.

68. Soetikno RM, Gotoda T, Nakanishi Y, Soehendra N. Endoscopic mucosal resection. Gastrointest Endosc 2003;57:567-79.

69. Hotta K, Fujii T, Saito Y, Matsuda T. Local recurrence after endoscopic resection of colorectal tumors. Int. J. Colorectal Dis 2009;24:225-30.

70. Gotoda T, Kondo H, Ono $\mathrm{H}$ et al. A new endoscopic resection procedure using an insulation-tipped electrosurgical knife for rectal flat lesions: Report of two cases. Gastrointest Endosc 1999;50:560-3.

71. Yoshida N, Naito Y, Sakai K, et al. Outcome of endoscopic submucosal dissection for colorectal tumors in elderly people. Int $\mathbf{J}$ Colorectal Dis 2010;25:455-61.

72. Saito Y, Sakamoto T, Fukunaga S, et al. Endoscopic submucosal dissection for colorectal tumors. Dig Endosc 2009;21:S7S12.

73. Niimi K, Fujishiro M, Kodashima S, et al. The long-term outcomes of endoscopic submucosal dissection for colorectal epithelial neoplasms. Gastrointest Endosc 2010;71:AB193.

74. Ishii N, Itoh T, Horiki N, et al. Endoscopic submucosal dissection with a combination of small-caliber-tip transparent hood and flex knife for large superficial colorectal neoplasias including ileocecal lesions. Surg Endosc 2010;24:1941-7.

75. Fujishiro M, Yahagi N, Kakushima N, et al. Endoscopic submucosal dissection of esophageal squamous cell neoplasms. Clin Gastroenterol Hepatol 2006;4:688-94.

76. Oda I, Gotoda T, Hamanaka H, et al. Endoscopic submucosal dissection for early gastric cancer: technical feasibility, operation time and complications from a large consecutive series. Dig Endosc 2005; 17:54-8.

77. Takizawa K, Oda I, Gotoda T, Yokoi C, et al. Routine coagulation of visible vessels may prevent delayed bleeding after submucosal dissection - An analysis of risk factors. Endoscopy 2008;40:179-83.

78. Isomoto H, Nishiyama H, Yamaguchi N, Fukuda E, et al. Clinicopathological factors associated with clinical outcomes of endoscopic submucosal dissection for colorec- tal epithelial neoplasms. Endoscopy 2009;41:679-83.

79. Tsunda S, Ogata S, Mannen K, et al. Case series of balloon dilation to treat a stricture caused by circumferential resection of the gastric antrum by endoscopic submucosal dissection. Gastrointest Endosc 2008;67:979-83.

80. Min BH, Chang DK, Kim DU, et al. Low frequency of bacteremia after an endoscopic resection for large colorectal tumors in spite of extensive submucosal exposure. Gastrointest Endosc 2008;68:105-10.

81. Itaba S, Iboshi Y, Nakamura K, et al. Low frequency of bacteremia after an endoscopic resection of the stomach. Dig Endosc 2011;23:69-72.

82. Nieponice A, McGrath K, Qureshi I, et al. An extracellular matrix scaffold for esophageal stricture prevention after circumferential EMR. Gastrointest Endosc 2009;69:289-96.

83. Sakurai T, Shukichi M, Miyata G, et al. Autologous buccal keratinocyte implantation for the prevention of stenosis after EMR of the esophagus. Gastrointest Endosc 2007;66:167-73.

84. Saito Y, Uraoka T, Matsuda T, et al. A pilot study to assess the safety and efficacy of carbon dioxide insufflation during colorectal endoscopic submucosal dissection with the patient under conscious sedation. Gastrointest Endosc 2007;537-42.

85. Deprez PH, Bergman JJ, Meisner S, et al. Current practice with endoscopic submucosal dissection in Europe: position statement from a panel of experts. Endoscopy 2010;42:853-8.

86. Coda S, Lee SY, Gotoda T. Endoscopic mucosal resection and endoscopic submucosal dissection as treatments for early gastrointestinal cancers in Western countries. Gut Liver 2007;1:12-21. 